\title{
Role of FNAC in diagnosis of parotid lesions
}

\author{
Ahmed Youssef ${ }^{1,2^{*}}$ (D) Daren Cope ${ }^{2}$, Sundus Alsedra ${ }^{1}$, Mohamed Zahran ${ }^{1}$ and Abdel Rahman El Tahan ${ }^{3}$
}

\begin{abstract}
Background: Salivary gland masses are considered challenging for diagnosis regarding its origin and whether benign or malignant. Unique features of FNAC as a safe and easy diagnostic procedure with little discomfort to the patient made it a favorable primary diagnostic tool. Information regarding the nature of parotid lesions whether being benign or malignant is the main objective of FNAC. We have done a restrospective study for FNAC for parotid masses performed in John Hunter hospital (Newcastle, NSW, Australia) along the peroid from 2014-2018. Histopathological correlation was done in 74 cases to test the accuracy of FNAC in diagnosis of parotid lesions.

Results: Of the total 74 FNAC done for parotid lesions in which a histopathological correlation was done, we get 46 (62.2\%) benign lesions (37 neoplastic and 9 non-neoplastic) while 28 (37.8\%) were malignant tumor.

Pleomorphic adenoma was the most common in benign tumor side (45.7\%) while SCC is the most common in malignant group (53.6\%). Compatibility between FNAC and histological diagnosis was found in 74\% (55/74), of which $78.3 \%$ in benign lesions (36/46) and in 68\% of malignant lesions (19/28). FNA cytology was true positive in $21 / 74$ cases (28.4\%) and true negative in $41 / 74$ (55.4\%) cases. We have $5(6.8 \%)$ false-negative and 7 (9.5\%) falsepositive results. As a result, we get sensitivity of $81 \%$, specificity of $85 \%$, and accuracy of $84 \%$.

Conclusion: The role of FNAC in diagnosis of primary salivary gland pathology is considered with some debate about sensitivity/specificity; however, sometimes it should be repeated or correlated with clinical/histopathological confirmation.
\end{abstract}

\section{Background}

Salivary gland masses are considered challenging for diagnosis regarding its origin whether being benign or malignant. They usually affect parotid, submandibular, sublingual, and minor salivary glands in descending order. Parotid accounts for $3 \%$ of all head and neck and $0.6 \%$ of all tumors of human body [1].

Parotid tumors are mostly benign (85\%), mostly of pleomorphic adenoma type, while mucoepidermoid carcinoma is the most common malignant tumor. Other causes of parotid masses such as metastatic cancers, inflammatory conditions, and lymphoma may also cause parotid gland masses [2, 3]. Histopathological examination offers the

\footnotetext{
*Correspondence: ahmedyouseef2002@yahoo.com;

Ahmed.Youssef@hnehealth.nsw.gov.au

'Department of Otolaryngology-Head and Neck surgery, Alexandria

University Hospital, Alexandria, Egypt

${ }^{2}$ Department of Otolaryngology-Head and Neck Surgery, John Hunter

Hospital, Newcastle, NSW, Australia

Full list of author information is available at the end of the article
}

final definitive diagnosis of tumor types after surgical resection in spite of risks and complications associated with parotidectomy. So, a less invasive reliable method of diagnosis is therefore often preferred, which can help with management.

Since 1920s, the concept of fine needle aspiration cytology (FNAC) started where it came into use simultaneously in Europe and the USA [4, 5]. FNAC is a diagnostic tool based on the morphological findings of individual or group of cells obtained using a needle [6]. This procedure was further developed in the 1950s and 1960s by the Karolinska Institute in Stockholm [7] and the Institut Curie in Paris [8]; then, it was popular in the 1970s. Nevertheless, Batsakis et al. [9] argued that parotid masses require surgery and that the preoperative FNAC has had little impact on clinical management. Other authors consider FNAC as a superior diagnostic tool compared to the combination of physical examination and radiological evaluation [10, 11], which cannot distinguish reliably between benign and malignant 
lesions. FNAC is a relatively painless, quick, and minimally invasive procedure that is usually conducted in the outpatient setting [12]. It is easy to perform and feasible with few contraindications. The only limitation is that it has been associated with variable sensitivity and specificity in differentiating malignant from benign disease. Moreover, high rates of non-diagnostic aspirations have been reported in the literature [13]. An open biopsy is another option that is not preferred because of the risk of tumor spillage, facial nerve injury, scarring, and fistula formation [6]. Currently, ultrasound-guided core biopsies (USCBs) have been described as a very reasonable option [14-18]. The use of large bore needles in core biopsies has been associated with tumor seeding along the needle tract in literature [19-21] making FNA a more convenient option.

\section{Methods}

We have done a restrospective study for FNAC for parotid masses performed in John Hunter hospital (Newcastle, NSW, Australia) along the peroid from 2014-2018. Histopathological correlation was done in 74 cases to test the accuracy of FNAC in diagnosis of parotid lesions.

FNAC was performed by a cytopathologist using a 23gauge fine needle attached to a 10-ml plastic syringe and employing a Cameco gun. Slides were air dried for DiffQuik staining, and an on-site, provisional cytopathologic diagnosis was rendered on all slides. Additional smears were prepared and fixed immediately in $95 \%$ ethanol for subsequent Papanicolaou staining. In some cases, needle rinses with balanced salt solution were used to make paraffin cell blocks, and 4-m thin sections were stained with hematoxylin and eosin.

Histological correlation of FNAC results with surgical specimen was done to confirm accuracy of cytological diagnosis.

\section{Results}

A total of 74 FNAC done for parotid lesions in which a histopathological correlation was done were reviewed in Table 1.

We get $46(62.2 \%)$ benign lesions (37 neoplastic and 9 non neoplastic) while 28 (37.8\%) were malignant tumors (Table 1). Pleomorphic adenoma was the most common in benign tumor side (45.7\%) while SCC is the most common in malignant group (53.6\%) (Table 1).

Compatibility between FNAC and histological diagnosis was found in $74 \%$ (55/74), of which $78.3 \%$ in benign lesions (36/46) and in $68 \%$ of malignant lesions (19/28) (Table 1).

FNA cytology was true positive in $21 / 74$ cases $(28.4 \%)$ and true negative in $41 / 74(55.4 \%)$ cases. We have 5
Table 1 Cytological diagnosis and final histological diagnosis

\begin{tabular}{ll}
\hline & Cytology \\
\hline Pleomorphic adenoma & 21 \\
Warthin tumor & 15 \\
Epidermoid cyst & 6 \\
Reactive lymph node & 3 \\
Sialectasia & 1 \\
Total (benign) & 46 \\
SCC & 15 \\
Malignant cells & 8 \\
Metastatic melanoma & 3 \\
Adenocarcinoma & 1 \\
Lymphoma & 1 \\
Total (malignant) & 28 \\
Total cases & 74
\end{tabular}

(6.8\%) false-negative and 7 (9.5\%) false-positive results (Table 2).

As a result, we get sensitivity of $81 \%$, specificity of $85 \%$, and accuracy of $84 \%$ as shown in Table 3.

\section{Discussion}

FNAC is a reliable diagnostic procedure with little discomfort to the patient. So, it is considered a useful diagnostic tool to differentiate between benign and malignant tumors of parotid masses. However, definite tumor type and grading is achieved through final histological examination.

The accuracy of FNAC depends on important factors like the experience of the clinician performing the procedure in addition to the experience of the pathologist in assessing the cytological sample. Inadequate cellularity or smears have been reported in 2 to $10 \%$ of cases in literature [22, 23], which can be explained by needle insertion outside the target tissue or because of necrosis, hemorrhage, or cystic areas in the tumor. So, repeating the sampling may be a good option to obtain more information [24].

Fakhry et al. has made a review that showed FNAC sensitivity ranging from 54 to $92 \%$ and a specificity ranging from 86 to $100 \%$, compared to his own study that showed a sensitivity of $80 \%$ and specificity of $89 \%$ [25].

Table 2 FNAC and histological results for diagnosis of malignancy

\begin{tabular}{llll}
\hline FNAC & \multicolumn{2}{l}{ Histological Diagnosis } & Total \\
\hline & Malignant Positive & Benign Negative & \\
Malignant Positive & $21(28.4 \%) \mathrm{TP}$ & $7(9.5 \%) \mathrm{FP}$ & 28 \\
Benign Negative & $5(6.8 \%) \mathrm{FN}$ & $41(55.4 \%) \mathrm{TN}$ & 46 \\
Total & 26 & 48 & 74 \\
\hline
\end{tabular}


Table 3 FNAC results

\begin{tabular}{ll}
\hline FNAC & $\%$ \\
\hline Sensitivity & 81 \\
Specificity & 85 \\
Accuracy & 84 \\
\hline
\end{tabular}

Another review done by Zbaren et al. mentioned that the accuracy ranged between 84 and 97\%, while the sensitivity range was from 54 to $95 \%$, and specificity ranged from 86 to $100 \%$. On the other hand, study showed the accuracy $84 \%$, sensitivity $64 \%$, and specificity $95 \%$ [26].

Our study illustrated a sensitivity of $81 \%$, a specificity of $85 \%$, and an accuracy of $84 \%$, in compatible with Stewart et al. that showed overall sensitivity, specificity, and accuracy of $92 \%, 100 \%$, and 98\% respectively [27], while Naeem et al. showed a sensitivity, specificity, and accuracy of $84 \%, 98 \%$, and $84-97 \%$ respectively [28]. Along Suzuki et al.'s study, sensitivity, specificity, and accuracy were calculated as $82.3 \%, 98.7 \%$, and $95.9 \%$ respectively [29]. Altin et al. showed sensitivity, specificity, and accuracy of $68.96 \%, 89.63 \%$, and $86.52 \%$ [30]. Feinstein et al. showed sensitivity of $75 \%$ and specificity of 95.1\% [31].

In our study, the most common benign tumor was pleomorphic adenoma while the most common malignant was squamous cell carcinoma in compatible with Bachar et al. [32]. However, Naeem et al. [28] and Altin et al. [30] reported mucoepidermoid carcinoma as the most common malignant tumor.

The overall concordance between FNAC and histology was $74 \%$ (55/74 cases) of which $78.3 \%(36 / 46)$ were benign cases and $68 \%(19 / 28)$ were malignant cases; this is slightly closer to the results obtained by Zbaren et al. [26] that showed $84 \%$ (benign) and $49 \%$ (malignant), while lower than results shown by Naeem et al. [28] which were $85 \%$ (total), $88 \%$ (benign), and $78 \%$ (malignant), and Al-Khafaji et al. [33] with 92\% (benign) and 84\% (malignant).

False-negative results were $6.8 \%$ close to the results obtained by Zurrida et al. [10] and other studies [26, 34, 35] but higher than results obtained by Naeem et al. [28], which is considered a problem so all parotid masses clinically suspected for malignancy with a nondiagnostic or negative finding on FNAC which required re-aspiration or a parotidectomy with frozen-section diagnosis must be performed [26].

False-positive results were reported $9.5 \%$ as high as compared to other studies ranging from 0 to $7 \%$ [26] and $10-12 \%[33,36]$.

\section{Conclusion}

The role of FNAC in the diagnosis of primary salivary gland pathology is considered with some debate about sensitivity/specificity; however, it should be correlated with clinical/histopathological confirmation.

\section{Abbreviations}

FNAC: Fine needle aspiration cytology; SCC: Squamous cell carcinoma

\section{Acknowledgements}

No acknowledgments are applicable.

\section{Authors' contributions}

All authors have read and approved the manuscript. AY: corresponding author. DC: surgical data. SA, MZ, AT: planning and organization of article by reviewing data and doing literature review.

\section{Funding}

Not applicable, no financial disclosure

\section{Availability of data and materials}

The datasets used and/or analyzed during the current study are available from the corresponding author on reasonable request.

\section{Declarations}

\section{Ethics approval and consent to participate}

The study was approved by John Hunter Hospital along with the approval of the data protection committee in April 2019. In addition to Alexandria Faculty of Medicine Ethics Committee in August 2019, reference no. 00018890. Consent to participate is not applicable as it is a retrospective study.

\section{Consent for publication}

Not applicable

\section{Competing interests}

The authors declare that they have no competing interests.

\section{Author details}

${ }^{1}$ Department of Otolaryngology-Head and Neck surgery, Alexandria University Hospital, Alexandria, Egypt. ²Department of Otolaryngology-Head and Neck Surgery, John Hunter Hospital, Newcastle, NSW, Australia.

${ }^{3}$ Department of Otolaryngology-Head and Neck Surgery, Aswan University Hospital, Aswan, Egypt.

Received: 25 March 2020 Accepted: 5 April 2021

Published online: 19 May 2021

\section{References}

1. Hugo NE, McKinney P, Griffith BH (1973) Management of tumors of the parotid gland. Surg Clin North Am 53(1):105-111. https://doi.org/10.1016/ S0039-6109(16)39936-4

2. Ali NS, Akhtar S, Junaid M, Awan S, Aftab K (2011) Diagnostic accuracy of fine needle aspiration cytology in parotid lesions. ISRN Surg 721525

3. Mavec P, Eneroth CM, Franzen S, Moberger G, Zajicek J (1964) Aspiration biopsy of salivary gland tumours. Correlation of cytologic reports from 652 aspiration biopsies with clinical and histologic findings. Acta Otolaryngol 58(1-6):471-484. https://doi.org/10.3109/00016486409121406

4. Dudheon LS, Patrick CV (1927) A new method for the rapid microscopical diagnosis of tumors. Br J Surg 15(58):250-261

5. Martin HE, Ellis EB (1930) Biopsy by needle puncture and aspiration. Ann Surg 92(2):169-181. https://doi.org/10.1097/00000658-193008000-00002

6. McGuirt WF, McCabe BF (1978) Significance of node biopsy before definitive treatment of cervical metastatic carcinoma. Laryngoscope 88(4):594-597. https://doi.org/10.1002/lary.1978.88.4.594

7. Mavec P, Eneroth CM, Franzen S, Moberger G, Zajicek J (1964) Aspiration biopsy of salivary gland tumors. Acta Otolaryngol (Stockh) 58(1-6):471-484. https://doi.org/10.3109/00016486409121406

8. Bonneau H, Sommer D (1959) L'orientation du diagnositc des tumeurs salivaires par la ponction a' l'aiguille fine. Pathol Biol 7:786-791

9. Batsakis JG, Sueige N, el-Naggar AK (1992) Fine-needle aspiration of salivary glands: its utility and tissue effects. Ann Otol Rhinol Laryngol 101(2):185188. https://doi.org/10.1177/000348949210100215 
10. Zurrida S, Alasio L, Tradati N, Bartoli C, Chiesa F, Pilotti S (1993) Fine-needle aspiration of parotid masses. Cancer 72(8):2306-2311. https://doi.org/10.1 002/1097-0142(19931015)72:8<2306::AID-CNCR2820720804>3.0.CO;2-E

11. Owen EERTC, Banerjee AK, Prichard AJN, Hudson EA, Kark AE (1989) Role of fine-needle aspiration cytology and computed tomography in the diagnosis of parotid swellings. Br J Surg 76(12):1273-1274. https://doi.org/10.1002/ bjs. 1800761217

12. Qizilbash AH, Sianos J, Young JE, Archibald SD (1985) Fine needle aspiration biopsy cytology of major salivary glands. Acta Cytol 29(4):503-512

13. Schmidt RL, Hall BJ, Wilson AR, Layfield $L$ (2011) A systematic review and meta-analysis of the diagnostic accuracy of fine needle aspiration cytology for parotid gland lesions. Am J Clin Pathol 136(1):45-59. https://doi.org/1 0.1309/AJCPOIEOCZNAT6SQ

14. Breeze J, Andi A, Williams MD, Howlett DC (2009) The use of fine needle core biopsy under ultrasound guidance in the diagnosis of a parotid mass. Br J Oral Maxillofac Surg 47(1):78-79. https://doi.org/10.1016/j.bjoms.2008.04. 016

15. Tighe D, Haldar S, Mandalia U, Skelton E, Ramesar K, Williams M, Howlett D (2014) Diagnostic investigation of parotid neoplasms: a 14 year experience of freehand fine needle aspiration cytology and ultrasound guided core needle biopsy. Br J Oral Maxillofac Surg 52(8):e66. https://doi.org/10.1016/j. bjoms.2014.07.074

16. Huang YC, Wu CT, Lin G, Chuang WY, Yeow KM, Wan YL (2012) Comparison of ultrasonographically guided fine-needle aspiration and core needle biopsy in the diagnosis of parotid masses. J Clin Ultrasound 40(4):189-194. https://doi.org/10.1002/jcu.20873

17. Haldar S, Mandalia U, Skelton E, Chow V, Turner SS, Ramesar K, Tighe D, Williams M, Howlett D (2015) Diagnostic investigation of parotid neoplasms: a 16-year experience of freehand fine needle aspiration cytology and ultrasound-guided core needle biopsy. Int J Oral Maxillofac Surg 44(2):151157. https://doi.org/10.1016/j.ijom.2014.09.025

18. Kesse KW, Manjaly G, Violaris N, Howlett DC (2002) Ultrasound-guided biopsy in the evaluation of focal lesions and diffuse swelling of the parotid gland. Br J Oral Maxillofac Surg 40(5):384-388. https://doi.org/10.1016/S02 66-4356(02)00189-4

19. Roussel F, Dalion J, Benozio M (1989) The risk of tumoral seeding in needle biopsies. Acta Cytol 33(6):936-939

20. Roussel F, Nouvet G (1995) Evaluation of large-needle biopsy for the diagnosis of cancer. Acta Cytol 39(3):449-452

21. Yamaguchi KT, Strong MS, Shapshay SM, Soto E (1979) Seeding of parotid carcinoma along Vim-Silverman needle tract. J Otolaryngol 8(1):49-52

22. Guyot JP, Obradovic D, Krayenbuhl M, Zbaeren P, Lehmann W (1990) Fineneedle aspiration in the diagnosis of head and neck growths: is it necessary? Otolarnygol Head Neck Surg 103(5):697-701. https://doi.org/1 $0.1177 / 019459989010300506$

23. Smith Frable MA, Frable WJ (1991) Fine-needle aspiration biopsy of salivary glands. Laryngoscope 101:245-249

24. Filipoulos E, Angeli S, Daskalopoulon D, Kelessis N, Vassilopoulos P (1998) Pre-operative evaluation of parotid tumours by fine-needle biopsy. Eur J Surg Oncol 24(3):180-183. https://doi.org/10.1016/S0748-7983(98)92895-5

25. Fakhry N, Antonini F, Michel J, Penicaud M, Mancini J, Lagier A, Santini L, Turner F, Chrestian MA, Zanaret M, Dessi P, Giovanni A (2012) Fine-needle aspiration cytology in the management of parotid masses: evaluation of 249 patients. Eur Ann Otorhinolaryngol Head Neck Dis 129(3):131-135. https://doi.org/10.1016/j.anorl.2011.10.008

26. Zbaren P et al (2001) Value of fine-needle aspiration cytology of parotid gland masses. Laryngoscope 111

27. Stewart CJ et al (2000) Fine-needle aspiration cytology of salivary gland: a review of 341 cases. Diagn Cytopathol 22(3):139-146. https://doi.org/10.1 002/(SICI)1097-0339(20000301)22:3<139::AID-DC2>3.0.CO;2-A

28. Naeem SA, Shabbir A et al (2011) Diagnostic accuracy of fine needle aspiration cytology in parotid lesions. Int Sch Res Netw Surg 2011:5

29. Suzuki M, Kawata R et al (2018) Values of fine-needle aspiration cytology of parotid gland tumors: a review of 996 cases at a single institution. Head Neck:1-8

30. Altin F, Alimoglu Y, Acikalin RM, Yasar H (2019) Is fine needle aspiration biopsy reliable in the diagnosis of parotid tumors? Comparison of preoperative and postoperative results and the factors affecting accuracy. Braz J Otorhinolaryngol 85(3):275-281. https://doi.org/10.1016/j.bjorl.2018.04. 015
31. Feinstein AJ, Alonso J et al (2016) Diagnostic accuracy of fine-needle aspiration for parotid and submandibular gland lesions. Otolaryngol Head Neck Surg 155(3)

32. Bachar $G$, Shkedy $Y$ et al Fine needle aspiration cytology for parotid lesions, can we avoid surgery? https://doi.org/10.1111/coa.13038.2016

33. Al-Khafaji BM, Nestok BR, Katz LR (1998) Fine needle aspiration of 154 parotid masses with histologic correlation. Cancer 84(3):153-159. https://doi. org/10.1002/(SICI)1097-0142(19980625)84:3<153:.AID-CNCR6>3.0.CO;2-P

34. Atula T, Greénman R, Laippala P, Klemi PJ (1995) Fine-needle aspiration biopsy in the diagnosis of parotid gland lesions. Diagn Cytopathol 15:185190

35. Pitts DB, Hilsinger RL, Karandy E, Ross JL, Caro JE (1992) Fine-needle aspiration in the diagnosis of salivary gland disorders in the community hospital setting. Arch Otolaryngol Head Neck Surg 118(5):479-482. https:// doi.org/10.1001/archotol.1992.01880050025005

36. Seifert G (1991) Histological typing of salivary gland tumors. In: World Health Organization International Histological Classification of Tumours. Springer, Geneva. https://doi.org/10.1007/978-3-642-84506-2

\section{Publisher's Note}

Springer Nature remains neutral with regard to jurisdictional claims in published maps and institutional affiliations.

\section{Submit your manuscript to a SpringerOpen ${ }^{\circ}$ journal and benefit from:}

- Convenient online submission

- Rigorous peer review

- Open access: articles freely available online

High visibility within the field

- Retaining the copyright to your article

Submit your next manuscript at $\boldsymbol{\sim}$ springeropen.com 